C O L A B O R A Ç Ã O E S P E C I A L

\title{
A LENIÊNCIA E VARGAS: FALAS DA HISTÓRIA
}

The Leniency towards Vargas: the narratives of history

La indulgencia hacia Vargas: los discursos de la historia

ELIZABETH CANCELLI ${ }^{I^{*}}$

DOI: http://dx.doi.org/10.1590/S2178-14942020000300002

'Universidade de São Paulo - São Paulo (SP), Brasil.

* Professora doutora livre-docente pela Universidade de São Paulo (cancellie@gmail.com)

(D) https://orcid.org/0000-0002-7511-9423

Artigo recebido em 01 de maio de 2020 e aprovado para publicação em 03 de julho de 2020. 


\title{
Resumo
}

Este artigo analisa correntes historiográficas que se debruçaram sobre os anos Vargas. Seu ponto de partida é o de que análises estruturais advindas fundamentalmente das Ciências Sociais acabaram por desenvolver uma visão leniente sobre esse período da história. Perspectivas críticas a essas interpretações contrapuseramse às teorias da modernização e sua sucedânea teoria da dependência, e questionaram, do ponto de vista teórico, a precedência da questão social como questão política. Mudanças de paradigmas de análise cruzaram as fronteiras dos limites nacionais, do etnocentrismo e da visão regional de história, da dependência e das disputas palacianas das elites políticas.

PALAVRAS-CHAVE: Era Vargas; Historiografia; Questão Social; Fascismo.

\begin{abstract}
This paper analyzes different historiographical perspectives focused on the Vargas' regime. Its starting point is that structural analyses derived mainly from the Social Sciences ended up developing a lenient view of this historical period. Critical analyses of these interpretations were opposed to the modernization theories, and its successive dependency theory, questioned, from a theoretical point of view, the precedence of the social question as a political issue. The changes that those new paradigms brought to historiography crossed the limits of national boundaries, ethnocentrism, and the regional view of history, dependence and the disputes of political elites.
\end{abstract}

KEYWORDS: Vargas Period; Historiography; Social question; Fascism.

\section{RESUMEN}

Este artículo analiza las corrientes historiográficas que se han centrado en los años Vargas. Su punto de partida es que los análisis estructurales derivados principalmente de las Ciencias Sociales terminaron desarrollando una visión indulgente de este período de la historia. Análisis críticos de estas interpretaciones se opusieron a las teorías de la modernización, y su sucesiva teoría de la dependencia, y cuestionaron, desde un punto de vista teórico, la precedencia del problema social como un problema político. Los cambios en los paradigmas de análisis cruzaron los límites de las fronteras nacionales, del etnocentrismo y de la visión regional de la historia, de la dependencia y de las disputas palaciegas de las élites políticas.

PALABRAS CLAVE: Era Vargas; Historiografía; Cuestión social; Fascismo. 
No mortal can keep a secret. If his lips are silent, he chatters with his fingertips; betrayal oozes out of him at every pore.

Freud (1956, p. 77-78)'.

$\mathbf{E}^{\mathrm{n}}$ m 1964, o historiador norte-americano Robert Levine chegou ao Brasil para conduzir a pesquisa do doutorado que cursava com Stanley Stein na Universidade de Princeton. Era o ano do golpe de Estado, e tocar neste assunto sensível, o legado varguista, era um problema nas terras brasileiras². Levine defendeu em 1970 sua tese The Vargas Regime: the critical years, que foi imediatamente publicada pela Columbia University Press. Tentou-se por duas vezes que a tradução de Raul de Sá Barbosa ganhasse as livrarias no Brasil, mas a censura do regime vetou a publicação. Somente em 1980, a Nova Fronteira trouxe a público o livro do historiador (Levine, 1980).

0 trabalho de Levine era inovador por várias razões. Em primeiro lugar, explorava 0 acervo de documentos de forma intensa, articulando, no sentido de chegar a análises políticas mais profundas, a riqueza de material aos relatórios e observações de época que coletou. Já no capítulo inicial ("0 quadro social e ideológico"), por exemplo, a primeira nota de referência faz alusão ao artigo de Agnes Waddell de 1931 publicado na Foreign policy reports (Levine, 1980: 59), associando-o aos despachos da embaixada brasileira nos Estados Unidos. Levine cruzou fontes oficiais brasileiras com o acesso privilegiado a acervos oficiais e particulares no país, além de ter feito muitas entrevistas. Priorizou, pela primeira vez na historiografia, arquivos policiais, o que lhe permitiria conclusões inéditas.

Em segundo lugar, o trabalho inovava ao sustentar a análise em tradição acadêmica fortemente ancorada nos princípios das teorias sociológicas do desenvolvimentismo dos anos 1950 - tradição à qual Florestan Fernandes, fortalecido pelas publicações de seus orientandos, era um dos maiores expoentes no Brasil. Nesses trabalhos, um dos pressupostos fundamentais de análise era a contraposição do que convencionaram classificar de sociedades modernas e sociedades tradicionais ${ }^{3}$. Nessa perspectiva, sua bibliografia de apoio vinculava-se a trabalhos como o de Albert Hirschman (Journeys toward progress: studies of economic policy making in Latin America, 1963), o de Jacques Lambert (Requirements for rapid economic and social development, 1963), o de seu orientador Stanley Stein (The Brazilian cotton manufacture: textile enterprise in an underdeveloped area, 1850-1950, 1957) e na coletânea de Irving Horowitz (Revolution in Brazil: politics and society in a developing nation, 1964), por exemplo ${ }^{4}$. Eram trabalhos caudatários do fundamento de que a estabilidade democrática era uma decorrência da modernização e da industrialização, como preconizara Seymour Martin Lipset em seu Some social requisites of democracy, de 1959. 
Além da matriz norte-americana, os trabalhos de Florestan Fernandes, como Pattern and rate of development in Latin America e o clássico Mudanças sociais no Brasil, de 1960, foram informando os fundamentos de análise de Levine sobre a sociedade brasileira no século XX. É recorrente em sua bibliografia a remissão a autores de formação uspiana, como Bresser Pereira, Fernando Henrique Cardoso, Octavio lanni e Paul Singer. Alguns economistas, outros sociólogos, mas todos caudatários da tradição modernizante.

Em terceiro lugar, o trabalho de Levine era inovador porque se calcava em pressupostos relativamente novos nas análises sobre o Brasil do período, em particular nas teses construídas por Samuel Huntington desde a segunda metade dos anos 1950. Huntington criticava a premissa praticamente consensual dos teóricos da modernização de que ela, a modernização, invariavelmente levaria à democratização: inspirados em Weber, tais teóricos acreditavam em uma espécie de recorrência evolutiva do desenvolvimento do capitalismo, buscando na modernização a instituição de um ethos que transformaria essas sociedades tradicionais, suas elites e suas gentes. Em linhas gerais, Huntington advogava que, nos países tradicionais, os processos de modernização não levavam à democracia, mas à grave instabilidade política, na medida em que novos segmentos sociais emergentes nessa modernização fariam pressão por espaço político, fator que geraria, ademais, insegurança. Em Political order in changing societies, texto que Levine tinha como referência, Huntington afirmava:

0 que foi responsável por essa violência e instabilidade? A tese principal deste livro é que essa violência e instabilidade foram em grande parte produto de rápidas mudanças sociais e da rápida mobilização de novos grupos em direção à política, juntamente com o lento desenvolvimento das instituições políticas. "Entre as leis que regem as sociedades humanas" [...] A instabilidade política na Ásia, África e América Latina deriva precisamente do fracasso em cumprir esta condição: a igualdade de participação política está crescendo muito mais rapidamente do que "a arte de se congregar". Mudanças sociais e econômicas - urbanização, aumento da alfabetização e educação, industrialização, expansão da mídia — ampliam a consciência política, multiplicam as demandas políticas, ampliam a participação política. Essas mudanças minam as fontes tradicionais de autoridade política e as instituições políticas tradicionais; elas complicam enormemente os problemas de criação de novas bases de associação política e novas instituições políticas que combinem legitimidade e eficácia (Huntington, 1968: 5, tradução livre)5.

Embora Huntington esteja aqui chamando a atenção para a necessidade de entender a instabilidade gerada pela modernização econômica no pós-guerra, o quadro teórico de análise é o de que a modernização em países sem tradição democrática geraria instabilidade. Citando James Madison, o autor sentencia: 
"A grande dificuldade reside nisso: primeiramente você deve permitir que o governo controle os governados; e, em seguida, obrigá-lo a se controlar". Em muitos países em processo de modernização, os governos ainda são incapazes de desempenhar a primeira função, muito menos a segunda. 0 problema principal não é a liberdade, mas a criação de uma ordem pública legítima. Os homens podem, claro, ter ordem sem liberdade, mas eles não podem ter liberdade sem ordem. A autoridade tem que existir antes que possa ser limitada, e é a autoridade que é escassa nos países em modernização onde o governo está à mercê de intelectuais alienados, insubordinados coronéis e estudantes rebeldes (Huntington, 1968: 5, tradução livre).

A questão estava agora assim posta: não era absolutamente estranho que para promover a modernização se recorresse a regimes que garantissem, em primeiro lugar, a ordem, a estabilização. Assim, a maior inovação do livro de Robert Levine residia justamente na formulação de seu problema: tentar entender a dinâmica política que teria garantido o passo gerador dessa modernização, a instalação da indústria de base. Ou, como diria Levine ao fim da introdução:

Vargas consolidou o seu poder, silenciando fontes potenciais de oposição, e sacrificando liberdades civis a fim de assegurar a estabilidade política e a unidade nacional [...] 0 temor de que grupos identificados com a ordem anterior a 1930 voltassem ao poder obcecava a tal ponto a classe média que ela abriu mão gostosamente dos luxos da democracia em troca de um governo forte num quadro autoritário (Levine, 1980: 32).

Ou mais adiante, quando ele cita Hélio Jaguaribe: "O processo — observou um brasileiro - era a contrapartida política da substituição das importações" (Levine, 1980: 256)7.

Para entender "o processo", o estudo de Levine centrou-se não só na dinâmica do desenvolvimento industrial do Brasil, mas especialmente na movimentação e no comportamento das elites e das classes médias emergentes - exemplares do novo ethos político capitalista, inovadoras em relação à sociedade tradicional e que, como sugere o autor, seriam capazes de abandonar o "constitucionalismo liberal das oligarquias". 0 foco de análise nas classes médias era, então, fundamental porque, associadas à burguesia emergente, elas promoveriam o nacionalismo econômico e o desenvolvimento do país, num reformismo de mudanças progressivas contra as oligarquias dominantes. Por essa razão, Levine ia buscar uma bibliografia que oferecesse suporte à compreensão da dinâmica de tal modernização, ocorrida sob a bandeira do nacionalismo. Assim, Levine utiliza-se da produção de Florestan Fernandes e Jacques Lambert, Fernando Henrique Cardoso, Octavio lanni e das teses de doutoramento de Warren Dean e de Richard Morse, este já com livro publicado ${ }^{8}$. Como o chileno Luis Ratinoff, a tese de Levine era a de que o nacionalismo dessas classes médias foi importante como força de pressão — chegando 
elas a ser progressistas - até consolidar suas vitórias (empregos públicos, serviços de saúde e educação, direitos de trabalho etc.). E mais, o nacionalismo desenvolvimentista de Vargas (leia-se modernização/substituição de importações) teria abafado as vozes contrárias ao autoritarismo político (Levine, 1980: 259).

Considerando tais pressupostos, Levine buscava, nos "anos críticos de Vargas" (1934-1938), compreender a base fundacional do Estado Novo. Isto porque o interregno (supostamente democrático) entre o governo provisório e o período um pouco além da decretação do Estado Novo, em 1937, teria sido de instabilidade política e, portanto, anterior à implantação de um regime capaz de iniciar o processo de industrialização ${ }^{9}$. De forma que 0 que Levine - bem como grande parte dos autores que baseavam suas análises nas teorias da modernização e posteriormente na teoria da dependência — chama de "populismo" de Getúlio era a implementação de uma controlada política urbana distributiva ${ }^{10}$. Para o autor, a instabilidade política estaria instaurada de maneira intensa na vida política e expressava-se nos embates da esquerda, da direita, da frente de oposição (Aliança Nacional Libertadora — ANL), passando por políticos liberais da Primeira República (ou "oligarquias" — sic), pelos tenentes e pelo Partido Comunista do Brasil (PCB), findando com a insurreição integralista de 1938. 0 "maquiavelismo" e o "populismo" de Vargas residiriam, justamente, na habilidade em estabilizar os atores políticos.

Na procura de ordem e de estabilidade, fundamentais para que o regime implementasse seu projeto de modernização, Levine traz uma quarta grande inovação: a importância que o aparato repressivo e a censura tiveram na estabilização do regime. Assim, articula-os não na perspectiva de que os desmandos criminosos da atuação policial correspondessem aos desvios de caráter da personalidade de Filinto Müller, mas como parte desse projeto de estabilidade política. De fato, para desconforto da maior parte da historiografia sobre Vargas, Levine afirma que, assentado em forte aparato de repressão e propaganda, Getúlio definitivamente não fora um "pai dos pobres", já que sua política de "direitos sociais e trabalhistas" era, na verdade, a maneira de controlar esse processo de modernização sem mudar a estrutura social ou a concentração de renda. Essa "revolução incompleta de Vargas", dizia ele em livro posterior, era consequência desse processo de modernização e das características pessoais de exercício de poder do ditador (Levine, 2001) ${ }^{11}$.

Mesmo que suas matrizes teóricas estivessem presas ao que a área de Ciências Sociais via como legítimo ou correto para pensar o Brasil, e até mesmo para entender as ditaduras latino-americanas nos anos 1960 e 1970, Levine abria perspectivas ao recorrer à certificação documental para, ao menos, tentar colocar por terra o "mito Vargas". Seria de esperar, por isso, que a tese de Levine tivesse grande repercussão no país. 
Entretanto, seguindo em grande parte o arcabouço das teorias da modernização e, como frisado, de sua consequente teoria da dependência, o trabalho de Boris Fausto, mesmo carente de pesquisa documental, e talvez justamente por isso, tornou-se referência de interpretações sobre a Era Vargas. (A primeira das muitas edições de A Revolução de 30: história e historiografia foi publicada em 1970 pela Editora Brasiliense.) Sobre ele, Ângela de Castro Gomes diria 38 anos depois:

[...] Fausto irá revisitar o período da Primeira República, sustentando sua futura tese que será reafirmada na coleção História da Civilização Brasileira: com os episódios de 1930, o Brasil não viverá nem uma revolução burguesa, nem uma revolução das classes médias, como sustentavam as interpretações correntes. Tal episódio deveria ser explicado em outra chave: a dos conflitos regionais intraoligárquicos, que vinham agitando a década de 1920 e envolvendo novos atores no jogo da política republicana (Gomes, 2008: 23).

E mais adiante:

A Revolução surge então, fundamentalmente, como produto da questão política do regionalismo, o que se constitui numa das mais significantes conclusões e contribuições do livro (Gomes, 2008: 33).

[...] De forma sintética Fausto lembra que afirmar a Revolução de 1930 como produto "de uma frente difusa em equilíbrio instável", reunindo dissidências oligárquicas e setores militares, além do apoio das classes médias e até do operariado, não respondia à questão de quem substituiria a hegemonia da oligarquia cafeeira. Então, assume o conceito de "Estado de Compromisso", tomado de Francisco Weffort, como a melhor resposta possível. Por essa razão, procura fixar os principais elementos da proposta interpretativa escolhida: como nenhum dos grupos que participam do movimento oferecesse legitimidade ao Estado, abre-se um "vazio de poder", o que conduz a um compromisso entre as várias frações de classe e "aqueles que controlam as funções do governo", sem vínculo de representação direta (Gomes, 2008: 35).

Há dois pontos-chave na interpretação de Boris Fausto: as críticas às teses dualistas presentes em "sociedades dependentes latino-americanas" e às teses de que 30 teria sido uma revolução das classes médias urbanas. Para Fausto, 1930 não foi uma revolução burguesa, mas um acontecimento marcante por colocar fim à hegemonia do capital cafeicultor — daí o advento do Estado de Compromisso, espécie de licença interpretativa ancorada na teoria da dependência e no recurso a Gramsci, apontando para a necessidade de estabilização social.

\section{A QUESTÃO POLÍTICA}

Ainda em 1972, Gláucio Soares publicou na Revista Mexicana de Sociología resenha bastante negativa sobre o trabalho de Fausto: 
Espero que seu autor prossiga seu trabalho de pesquisa, coletando novas informações e novos dados que são indispensáveis, utilizando-os de maneira sistemática. A informação factual apresentada não constitui novidade, é errática e selecionada pelo autor. Outro conjunto de informações, como trechos de discursos, poderia ser retirado das mesmas fontes para ilustrar posições radicalmente diferentes. No meu entender, a tarefa de pesquisa está longe de completa e requer imaginação metodológica de todos os que pretendem estudar o problema. A diferença entre a execução e a não execução dessas pesquisas pode ser a diferença entre substituir uma série de mitos por outros ou substituir os mitos por um trabalho científico (Soares, 1972).

Pouco depois, em 1978, numa análise abertamente crítica às teorias da modernização, Maria Sylvia de Carvalho Franco, em trabalho sobre o Instituto Superior de Estudos Brasileiros (ISEB), ia um pouco além na avaliação dos parâmetros teóricos estruturantes de análises como a de Fausto. Tratando das miragens do jargão científico, ela postulava que o autoritarismo vinha, com a utilização de definições indemonstradas, disfarçado de revolução social, construindo uma realidade em que nação, comércio e indústria se antropologizam como sujeitos da história, na mira do progresso, teleologicamente, em direção à ordem capitalista. Segundo essas definições, tais premissas teriam tornado possível esquecer a crítica às ideologias e sua historicidade, inocentando-as (Franco, 1978: 115 e 209). Diria mesmo, em 2011, explicitando suas críticas, que

Na produção desse ideário, a Faculdade de Filosofia não saiu de mãos limpas ou vazias: ela ofereceu um pensamento diverso do produzido pelo ISEB, certamente menos vinculado à prática política, mas não faltou na tarefa de fornecer o substrato doutrinário para o desenvolvimentismo e suas reformas. [...] Tomou então grande vigor a teoria da dependência, que se encarregou de apontar as teias de aranha do marxismo, repentinamente tornado obsoleto e necessitando revisões, face às novas formas assumidas pelo capitalismo, notadamente o desaparecimento das determinações de classe. Mais outra faceta da apologia do progresso, cuja propaganda atravessou novamente a sociedade (Franco, 2011).

0 texto de 1978 tornava públicas as críticas que Maria Sylvia vinha fazendo ao grupo em torno de Florestan Fernandes e do qual ela, no início, fizera parte, até que profundas divergências teóricas a tivessem afastado. Ela e Marilena Chauí externaram, em livro conjunto, a maneira crítica como uma gama expressiva de pensadores vinha-se posicionando intelectual e politicamente em várias universidades brasileiras. Tratava-se de um rompimento, especialmente com as representações acadêmicas:

- $\quad$ presas à valorização dos mitos de identidade nacional (fossem quais fossem);

- de uma pseudoincompletude burguesa; 
- da procura dos tipos ideais weberianos, do ethos das classes médias e da burguesia;

- da aposta em modelos de desenvolvimento econômico como explicação do mundo dos homens;

- da busca desenfreada e incessante de um standard de comportamento para 0 homem brasileiro;

- da história brasileira como carecendo de organização e consistência próprias, explicada sempre com base no vazio, naquilo que ela deveria ser, mas não é.

Ou seja, as autoras apontavam para uma historiografia de rompimento com as representações que buscavam nos "males do passado" as justificativas intelectuais e políticas para projetos de Brasil'12. Na Apresentação de Ideologia e mobilização popular, Marilena Chaú $(1978)^{13}$ chama atenção, de forma incisiva, para o fato de que encontrara, na bibliografia relativa à Primeira República, uma impressionante similaridade de abordagens. Em sua quase totalidade, os estudos se distanciavam da análise dos sujeitos (e, portanto, do discurso e da ação dos homens) para se aterem aos predicados (àquilo que resulta da ação dos sujeitos, como, por exemplo, o Estado). Chauí concluiu que, em virtude dessa inversão, existiam eixos permanentes nas análises e que, nelas, a história do país resultaria da combinação:

- conflituosa das querelas da luta de classe dominante, incapaz de hegemonia;

- do despreparo e imaturidade da classe operária, sempre manipulada;

- do radicalismo inoperante das classes médias, sempre rebocadas;

- e do peso do capitalismo internacional avançado sobre o passado periférico. (Chauí, 1978: 22).

A historiografia teria construído uma história não do que foi, mas do que "teve de ser". Essa, digamos assim, anomalia historiográfica - a do que teve de ser — ter-se-ia constituído sobre um arcabouço conceitual que parte do que falta. Condicionantes que, do ponto de vista da pesquisa, a nosso ver, apontam para a procura da comprovação do que deve vir a ser. É dessa forma que se torna possível a construção das categorias de tardio, retardado, atrasado, de despreparado e imaturo e de ideias fora do lugar ${ }^{14}$. Tais postulações subentendem o estabelecimento não só de um parâmetro de modernidade, mas também de um encadeamento histórico evolutivo, de uma linha do tempo em direção a alguma coisa.

De forma avessa à tradição historiográfica, resultado de anos de trabalho em arquivos no Brasil, nos Estados Unidos e na Europa, Paulo Sérgio Pinheiro enfrentou a questão política dos anos Vargas de forma a privilegiar projetos políticos, suas heranças e as estratégias de 
poder de atores sociais. Mesmo tendo centrado seus estudos nas estratégias do PCB para 0 movimento de 1935, a metodologia transdisciplinar — para usarmos nomenclatura contemporânea - utilizada pelo autor ao analisar o acervo documental ressalta a miopia do PCB em relação à centralização do poder em Getúlio, à manipulação dos sindicatos, à formação de um estado policial e de seu aparato de repressão e à força do corporativismo. Para Pinheiro, Vargas enfatizara o recrudescimento dos abusos cometidos pelo Estado, no Brasil, durante o período anterior ao Estado Novo: prisões arbitrárias, tortura, execuções e deportações e as recorrências ao Estado de Sítio. A historiografia, aponta ele, tratava com enorme leniência os anos de poder de Vargas até o golpe que ele mesmo arquiteta em 1937. Segundo Pinheiro, e concordamos com ele, o governo provisório de 1930-1934 já era uma ditadura — interrompida por um brevíssimo período que seria retomado pelo golpe de 1937 (Pinheiro, 1991: 269)

0 trabalho de Pinheiro fazia emergir um incômodo aos historiadores: estaria a leniência historiográfica assentada na forma pela qual a questão política fora negligenciada pela questão social? Ou, disfarçada de revolução social, como sublinharam Maria Sylvia e Chauí, assentada em pressupostos teleológicos de que a esfera pública fora esvaziada e mascarada pela questão social? Ou seja, o exercício de poder, o caráter ditatorial teria, de certa forma, sido redimido?

É notório, a esse respeito, a forma com que a contracapa da primeira edição de $A R e$ volução de 1930 de Fausto já inscrevera historiograficamente como a questão política cederia terreno a este novo lugar, o da questão social:

A política de marginalização pura e simples, realizada pelas velhas classes dominantes, não tinha mais condições de se sustentar. Se na plataforma da Aliança Liberal já se encontravam os traços de um maior interesse pelo chamado problema social, as agitações operárias dos primeiros anos da década de trinta acabaram por "sensibilizar" o governo em definitivo (Fausto, 1970: contracapa, grifo nosso).

Na virada dos anos 1970/1980, alguns autores realizaram, ultrapassando os limites da conceituação de populismo de Fausto, uma renovada interpretação histórica sobre a Era Vargas - embora mantivessem a mesma chave teórica do autor. A chave de interpretação não partia mais do "populismo", mas ia além dele. Houve aqui a preocupação em resgatar a luta e os avanços da classe trabalhadora, ou de suas lideranças, como lutas contra uma espécie de "liberalismo excludente"! 0 princípio interpretativo partira principalmente das postulações de Wanderley Guilherme dos Santos em A práxis liberal no Brasil: dever-se-ia ficar atento aos diversos tipos de autoritarismo e, em particular, ao autoritarismo instrumental. "O Estado Novo", diz ele, "deu forma ao Estado forte pretendido pelos autoritários instrumentais": 
Os trabalhadores urbanos foram reconhecidos como membros plenos da sociedade civil, portadores de demandas legítimas, embora os canais de articulação fossem autorizados e patrocinados pelo governo. Uma mistura paradoxal de medidas econômicas liberalizantes, associadas ao aumento da intervenção regulatória nas relações sociais, e complementadas por ocasionais e intermitentes políticas de redistribuição" (Santos, 1978: 50).

Adiante, Santos conclui a sequência "lógica" de pensamento que marcaria profundamente a historiografia brasileira:

Somente depois da crise de renúncia de Jânio Quadros, com João Goulart no poder, é que uma espécie de autoritarismo instrumental tentou se firmar no cenário político brasileiro. Sua meta não era, entretanto, a liberalização da sociedade, nem mesmo da economia — mas, ao contrário, os objetivos visados pela nova versão do autoritarismo instrumental eram a intervenção do Estado, o nacionalismo e o maior avanço possível em direção ao socialismo. (Santos, 1978: 50).

Nessa sequência, essa interpretação do passado não só legitimava o primeiro período Vargas (1930-1945) pelo reconhecimento que teria dado à classe trabalhadora ${ }^{15}$, como prenunciava sua interpretação teleológica sobre a história política do Brasil até o golpe de 1964. Na verdade, segue uma interpretação, vigente nos anos 1970, sobre o surgimento e a consolidação de uma nova forma de dominação autoritária: a coalizão de militares, burguesia e burocracia estatal. Coalizão que fez surgir um novo tipo de autoritarismo, diferente dos anteriores, que não tinha na oligarquia fundiária sua base. Seria fruto de nova etapa de modernização. Uma modernização que não fortalecia as instituições, mas visava conter a luta de classes em meio à crise econômica pela qual passavam países "periféricos", vítimas de um modelo estrutural de acumulação ${ }^{16}$. Aqui, Guilhermo O'Donnell cunharia o termo "Estado burocrático autoritário". O período Vargas não seria esse tipo de ditadura instrumental, já que teria reconhecido o trabalhador urbano como "portador de demandas legítimas".

Em 1982, a editora Zahar lançou Estado Novo: ideologia e poder, de Lúcia Lippi, Mônica Velloso e Ângela da Castro Gomes (Lippi, 1982: 8). A proposta do livro vinha ao encontro das referidas postulações de Wanderley Guilherme e das que Bolivar Lamonier formulara em 1974:

0 paradoxo da mobilização autoritária é precisamente este: a fim de ativar grandes massas, 0 poder é obrigado a criar símbolos que, se efetivamente comunicados, estabelecem o contraponto para que elas se "objetifiquem" e se constituam subjetivamente como grupo. Não quero dizer com isso que tal processo se dê com facilidade, pois ele é obviamente dependente da organização de estruturas organizacionais e de atividades concretas e recorrentes (Lamounier, 1974: 86). 
0 estudo das representações dos anos 1930 tornara-se assim fundamental, pois adentrar a simbologia tornava possível afastar o regime de "uma identificação aparentemente óbvia com o fascismo", como era dito. Partia-se do princípio de que um quadro comparativo ou de confronto com outros regimes só poderia ser possível se "tivermos claro o que foi a proposta deste, quais suas metas e objetivos e de que modo se construiu a integração de diferentes segmentos sociais em um projeto comum, autoritário e nacionalista" (Lippi, 1982: 8), numa espécie de contexto de modernização em curto prazo em que o Estado forte fosse capaz de conter o ritmo das demandas sociais (Lippi, 1982: 28). 0 sentido inovador do Estado Novo ${ }^{17}$ - o "projeto político-ideológico extremamente bem articulado" — residiria, sobretudo, no convencimento acerca da preeminência de uma nova ordem, centrada no fortalecimento do Estado" (Velloso, 1982: 71), capaz de "sua dimensão mais inovadora: o enfrentamento da questão social" (Gomes, 1982: 115).

Um parágrafo de um dos capítulos mais citados do livro, O redescobrimento do Brasil, de Gomes, deixa clara a perspectiva de inovação que estaria, para essa tradição de pensamento, sendo articulada na Era Vargas:

A condenação da liberal democracia acarreta uma rejeição ao conceito e também ao próprio termo. É interessante observar que, no caso do Estado Novo, a mesma condenação à democracia-liberal vem acompanhada pelo esforço sistemático de recuperação da "democracia" por oposição ao liberalismo (Gomes, 1982: 145-146, grifo nosso).

Os três trabalhos que compõem o livro de 1982 eram fruto de pesquisas cuidadosas e de alto padrão. Procuravam desvendar não só as linhas mestras de pensamento político na Era Vargas, com o estudo das revistas Cultura Política e Ciência Política, mas debruçavam-se sobre os principais ideólogos do regime. Ao fazê-lo, colocavam um novo desafio à frente: recompor a democracia varguista (!) por meio da cidadania adquirida pela conquista de direitos sociais, graças à atuação de dois atores políticos "com laços profundos": a classe trabalhadora e o Estado. Esse movimento de conquista social seria chamado de "invenção do trabalhismo": o trabalhismo seria o resultado de um grande projeto político-ideológico de "participação política que conceituava cidadania, democracia, política" (Gomes, 1988: 11).

Retomando o que vínhamos argumentando, a definição da cidadania baseada na questão social tornou-se alvo de profundas discordâncias historiográficas, postuladas, como vimos, por Pinheiro, Franco e Chauí, por exemplo. 0 comportamento massificado, o regime de opressão, a repetição de slogans, a aposta na máquina de propaganda, a unicidade nacionalista, a criação de inimigos, a concepção orgânica de sociedade, a soberania absoluta do Estado, a liderança carismática, o salvadorismo político e o papel da polícia foram analisados 
por correntes historiográficas que não só eram críticas às teorias da modernização e sua sucedânea teoria da dependência, mas também questionavam, do ponto de vista teórico, a precedência da questão social como questão política por excelência. Ou seja, a análise histórica debruçava-se sobre a vida ativa, discurso e ação, como fundadores de projeto político. Nesse sentido, como discurso e ação, essência da esfera pública, revelou o caráter do projeto político da Era Vargas.

Para seguir adiante em seu fazer historiográfico, esse conjunto de pesquisas afastou-se das Ciências Sociais e buscou na História e na Filosofia Política a parceria teórica para pensar as vigas ideológicas e de ação do Regime Varguista e de suas estratégias de dominação. 0 uniformismo e o conformismo pregados pelo regime como estratégia de domínio, especialmente por meio do nacionalismo e do desaparecimento do indivíduo, receberam uma leitura crítica embasada na constatação de que o regime apagara a distinção entre polis (esfera pública) e o oikos/idion (esfera privada). Ou, como diria Roberto Romano (1981: 22-23) em Conservadorismo romântico: origem do totalitarismo:

A relativização absoluta do indivíduo, e sua inserção numa comunhão coletiva, assegurada pela propaganda e pelo trabalho dos intelectuais orgânicos, mostrou os limites das experiências comunitárias realizadas em larga escala no plano político: o fantasma da unidade social sempre termina por apagar as diferenças no interior da vida pública, à força do silêncio ou da repressão física direta sobre os oponentes.

Nessa linha, Carlos Alberto Vesentini e Edgar de Decca escreveram A revolução do vencedor, publicado em 1976. Os autores criticam a apropriação pela historiografia do marco "1930", demonstrando, com a análise de discursos de época, como esse marco se constituiu em divisor de uma periodização histórica fruto da memória política do vencedor. Um exercício de poder que refez a história política do Brasil, dando a 1930 o status de um novo começo, de transição, de ruptura "do domínio oligárquico", sem que a historiografia se desse conta de que se tornara refém dessa memória do vencedor:

Essa construção supõe certo conjunto de temas, daí derivados, que a bibliografia em geral e a historiografia em particular consideram objeto de estudo. Assim, temas como política oligárquica, fatos tipo revolução de 1930 e revolução de 1932, atores como oligarquia e os tenentes continuam sendo exaustivamente examinados, embora a maior parte desses trabalhos não tenha se preocupado com a crítica da ideia que substantiva essa refinada construção (Decca e Vesentini, 1976: 62).

0 artigo pressupunha a presença de movimento operário múltiplo, de uma população urbana politicamente ativa, de uma industrialização não circunscrita à "artificialidade", 
ao "atraso" tecnológico ou às plantas industriais com baixa concentração de capital fixo e formas de trabalho não assalariado que se compatibilizavam com o capital ou mesmo com a industrialização. Mais ainda, não assumia o termo "velha" da Primeira República — discursividade do vencedor, dos que tinham como projeto político antagonizar-se ao "liberalismo decadente" e daí se autoproclamarem "revolucionários".

Foi Stella Bresciani quem ampliou a discussão com uma crítica ainda mais aguda: o fato de a historiografia não só estar se apropriando do marco, mas da construção ideológica que fez o vencedor. Ela revela o que chamaria de "a problemática da relação entre o movimento da História e a fala da História". A fala da História de fato não interroga o movimento da história, sua construção ideológica (Bresciani, 1977: 10), mas se alimenta dela. Construir um novo trabalhador, responder aos anseios da classe trabalhadora e transformar cada um desses trabalhadores em cidadão consciente, promover os recursos para questões vitais, construir a verdadeira nação e a verdadeira democracia, iniciar um novo marco na história, criticar o ideário liberal como inábil e excludente, construir uma democracia sem "ideias importadas" e, acima de tudo, ingressar em um novo tempo, o tempo da democracia-autoritária, são construções ideológicas que Bresciani identifica em Oliveira Vianna, um dos principais ideólogos do regime, e que foram incorporadas pela historiografia: "A disputa é travada, pois, entre conceitos - ao de estado democrático-liberal é contraposto o conceito de estado democrático-autoritário" (Bresciani, 1977: 19, grifo nosso).

Muitos anos depois, Bresciani voltou a discutir a apropriação que a historiografia faz dos lugares-comuns de um leque expressivo de "intérpretes do Brasil". Publicado em 2005, O charme da ciência e a sedução da objetividade: Oliveira Vianna entre intérpretes do Brasil resgata chavões do pensamento brasileiro: as premissas de inadequação do povo, de sua ignorância/sabedoria, sua inconsciência, "bestialização", de ser belo e grotesco e a necessidade da presença política de lideranças sensíveis, firmes e pragmáticas - como os "autoritários instrumentais" de que fala Wanderley Guilherme. Um aprisionamento, portanto, da historiografia e das Ciências Sociais a pressupostos acabados e aceitos que perpassam as representações históricas, literárias e políticas do Brasil ${ }^{18}$.

Se nas falas da História os lugares-comuns comprometeram o aparato teórico das análises, Kasumi Munakata voltou-se, em extensa pesquisa, para a legislação trabalhista que questionava a defesa do caráter de "cidadania adquirida" pelos trabalhadores com a outorga de direitos sociais supostamente ocorrida durante o período getulista; recupera, então, a crescente legislação estatal que na verdade controla o mundo do trabalho, absorve as antigas conquistas operárias e elimina qualquer possibilidade de conflito de classe (Munakata, 1981: 72 e segs.). Munakata analisa a aceitação do movimento liderado pelos comunistas 
do controle do mercado de trabalho pelo Estado e a derrota dos trabalhadores corporificada com a Consolidação das Leis do Trabalho (CLT) (Munakata, 1981: 102 e segs.). A opção do corporativismo, de que Vargas fará uso como um dos primeiros atos de governo, seria no intuito de buscar leis reguladoras do trabalho (Munakata, 1981: 64). Todo o espaço social passa a ser ocupado pelo Estado, cabendo-Ihe, também pela absorção dos sindicatos, redefinir as relações de igualdade dos indivíduos perante a lei (capital e trabalho).

É nesse particular que gama substancial de trabalhos sobre a chamada Era Vargas se desprendeu das teorias da modernização e da psicologia de interesses, e voltou-se para a investigação sobre as representações da modernização, do demiurgo, do pai dos pobres, dos saberes, das famílias, da política de massas; questionou o tipo de fontes que vinha sendo utilizado, o aporte teórico e seus pressupostos de pesquisa: o "populismo", o "trabalhismo", o "compromisso", o "povo", o "atraso", o "partido". Essa ruptura teórica, pode-se dizer, abandonou a teleologia, o cunho nacionalista, os esquemas interpretativos e a absorção de pressupostos político-partidários à fala historiográfica. Fugiu, enfim, dos grandes determinismos estruturais e sistêmicos e da ressurreição integral do passado, da história evolutiva, "prolongamento da linha de desenvolvimento do passado reconstituído" (Burguière, 2001: 365), e voltou à história complexa, numa resistência à apologia do desenvolvimento. Essa historiografia analisaria projetos políticos, seus discursos e sua ação, rompendo com a tradição da procura de "modelos de análise" e da "aplicação explicativa de teóricos". 0 pressuposto das investigações passou a ser a diversidade e não a desigualdade, o suporte teórico reflexivo não pôde nem se constituiu com base no atraso, mas na medida em que se deixou surpreender pela documentação e pelo discurso ${ }^{19}$. Daí, por exemplo, ter encontrado a brutalidade, a força e a violência do totalitarismo como formas de controle das massas, a manutenção do regime e da propaganda, o controle social, a implementação do Estado dual (um da Lei, outro das prerrogativas), o medo, a criação de inimigos, o controle nas ruas, a censura. Estudou o papel da polícia no regime e o papel do terror. Em suma, desvelou a deificação da questão social como a questão política por excelência.

Essa historiografia alternativa construiu uma outra fala da História ${ }^{20}$. Tratou de trazer a complexidade e a interconectividade da história da humanidade para analisar os Estados, as instituições, os processos, as crenças e as redes que se formam e transcendem os espaços politicamente definidos como espaços nacionais; não no sentido de colocar a nação em um contexto mais amplo, mas de buscá-la relacionando-a com seu tempo (Keohane e Nye Jr., 1970/1971; Krasner, 1983). A análise tanto da política como da produção de ideias sobre política pressupôs, por isso, o abandono da teleologia e de noções que limitavam, por sua conceituação, a premissa de que atores nacionais figurariam como espécie de outsiders histó- 
ricos (Chalmers, 1993): muito mais pacientes do que homens capazes do discurso e da ação, como enfatiza Arendt ao pensar a condição humana, ou seja, a própria história (Arendt, 1983: 34) ${ }^{21}$. Esse outro tipo de fazer historiográfico foi possível justamente em decorrência de uma mudança de paradigmas de análises em que se cruzam as fronteiras dos limites nacionais, do etnocentrismo e da visão regional de história, da dependência e das disputas palacianas das elites políticas.

Nessa outra fala, as vigas ideológicas dos anos Vargas foram analisadas como forma de esvaziamento da esfera pública, parte de um discurso futurístico de sociedade que suprimiu o presente e ofereceu, em troca, a ilusão de uma sociedade do avenir, num regime que, afinal de contas, se sustentou no significante mestre da ideologia de seu tempo: o fascismo ${ }^{22}$. Não há leitura peculiaríssima de E. P. Thompson que possa modificar esse fato ${ }^{23}$. Por fim, não são necessários vetores de definição do conceito de fascismo (partido único, militarismo, imperialismo etc.) para entender a Era Vargas. Uma leitura refinada da documentação, teórica e empiricamente aliada à distância que nos dá o tempo, mostra-nos caminhos.

\section{NOTAS}

1 Dora: fragment of an Analysis of a Case of Hysteria (1956). Tradução livre: "Nenhum mortal pode guardar um segredo. Se os lábios estão em silêncio, falam as pontas dos dedos; a traição Ihe escorre por todos os poros".

2 Na longa preparação para desencadear o golpe de Estado em 1964, dizia-se que uma substituição para a fé e para os valores morais estaria sendo achada ou no materialismo do comunismo ou na "dedicação nacionalista ao sangue e à terra", ou seja, ao nacionalismo exacerbado, como preconizado pelos herdeiros de Getúlio (Torres apud Cancelli, 2017: 97).

3 São as teorias liberais do desenvolvimentismo, cujo epicentro foi primeiramente a escola de Sociologia de Chicago, depois acompanhada, especialmente, por Columbia e Harvard. Notabilizaram-se não só pela aposta na democratização por meio da modernização e da industrialização para o combate à miséria e ao totalitarismo, como pelo rechaço ao ensaísmo, com forte investimento na pesquisa empírica e na construção de teorias, métodos e técnicas de investigação em torno de temas candentes e fundamentais para os estudos sobre o desenvolvimento, a democracia e seu consequente combate ao que classificaram como regimes totalitários.

4 Outros expoentes foram Richard Morse, em suas pesquisas sobre a industrialização em São Paulo, e Thomas Skidmore, em texto que explora o experimento brasileiro da democracia (Politics in Brazil: 1930-1964: an experiment in democracy). Tal texto acabou traduzido como 
Brasil: de Getúlio a Castelo (1930-1964), revelando o aspecto evolutivo das "transformações" políticas brasileiras.

5 No original: "What was responsible for this violence and instability? The primary thesis of this book is that it was in large part the product of rapid social change and the rapid mobilization of new groups into politics coupled with the slow development of political institutions. 'Among the laws that rule human societies' [...] The political instability in Asia, Africa, and Latin America derives precisely from the failure to meet this condition: equality of political participation is growing much more rapidly than 'the art of associating together'. Social and economic change - urbanization, increases in literacy and education, industrialization, mass media expansion - extend political consciousness, multiply political demands, broaden political participation. These changes undermine traditional sources of political authority and traditional political institutions; they enormously complicate the problems of creating new bases of political association and new political institutions combining legitimacy and effectiveness". 6 No original: "The great difficulty lies in this: you must first enable the government to control the governed; and in the next place oblige it to control itself". In many modernizing countries governments are still unable to perform the first function, much less the second. The primary problem is not liberty but the creation of a legitimate public order. Men may, of course, have order without liberty, but they cannot have liberty without order. Authority has to exist before it can be limited, and it is authority that is in scarce supply in those modernizing countries where government is at the mercy of alienated intellectuals, rambunctious colonels, and rioting students

70 autor cita aqui: Hélio Jaguaribe, The dynamics of Brazilian Nationalism. A análise também está ancorada no trabalho de Luis Ratinoff, The new urban groups: the middle classes.

8 Especificamente: Florestan Fernandes e Jacques Lambert, Le Brésil. Structure sociale et institutions politiques; Octavio Ianni, Indústria e desenvolvimento social no Brasil; Fernando Henrique Cardoso, The industrial elite; Warren Dean, São Paulo Industrial Elite, 1890-1960; Richard Morse, From community to metropolis: a biography of São Paulo, Brazil. A diretriz teórica de Fernandes ficou conhecida como sociologia do desenvolvimento.

9 Industrialização periférica, ou desenvolvimento do capitalismo retardado ou tardio, como o período ficou largamente conhecido.

$10 \mathrm{Na}$ historiografia, as vertentes que endossam a chave populista como explicação para 0 "Estado de Compromisso" pós-1930 e a "política de massas" partem, na maioria das vezes, do trabalho de Francisco Weffort, Raízes sociais do populismo em São Paulo, de 1965, e de seus textos de 1967 e 1978. Entre historiadores, destacam-se os trabalhos de Boris Fausto 
sobre a Revolução de 30. Sobre o conceito de "populismo" no Brasil, Gomes dá um panorama interessante para nossa discussão (Gomes, 2001: 17-53). As formulações de Gino Germani e Torquato de Tella, base de incorporação da terminologia nas Ciências Sociais, partiam justamente da premissa de que o populismo ocorria em situações de transição, do atrasado para o moderno. Para uma crítica à utilização do "Estado de Compromisso" e às peculiaridades do país, ver Munakata (1984).

11 A publicação nos Estados Unidos foi em 1998. Para Levine, Vargas não tinha ideologia.

12 Nessa gama, a crítica ia dos pensadores do ISEB e da Comissão Econômica para a América Latina e o Caribe (CEPAL), passando por Florestan Fernandes, Celso Furtado, Sérgio Buarque de Holanda, Boris Fausto, Fernando Henrique Cardoso e Fernando Novaes até os chamados "modernistas", como Paulo Prado.

13 Para entender o pensamento do integralismo dos anos 1930, Chauí fez uma análise dos trabalhos que, historicamente, vinham tentando interpretar os anos 1920 e 1930.

14 Nessa perspectiva, do que não está no seu lugar, os trabalhos de Roberto Schwartzman, Ao vencedor as batatas, e o de José Murilo de Carvalho, Os bestializados da República, apresentam uma espécie de complementaridade.

15 Embora o trabalho de Wanderley Guilherme dos Santos fosse de 1978, já em 1975 Paulo Sérgio Pinheiro indicava e lamentava essa tradição que não só encarava o período republicano anterior a 1930 como de trevas, como apontava a irrelevância do movimento operário antes da outorga varguista (Pinheiro, 1975: 10).

16 Essa tradição de interpretação tem em O'Donnell seu maior expoente.

17 Ao falar sobre o movimento operário no Brasil, Michael Hall faz uma observação interessante sobre o caráter peculiar na história: "Acho que todas as historiografias nacionais tendem a considerar a experiência do seu país como única e peculiar, embora haja uma insatisfação crescente entre os historiadores com esse tipo de abordagem" (Fontes; Macedo, 2016).

18 Sobre o livro de Bresciani, ver Cancelli (2006).

19 Como chama atenção Michael Foucault ao longo de sua obra.

20 Citamos como importantes nessa bibliografia: Edgar de Decca, 0 silêncio dos vencidos; Carlos Alberto Vesentini, A teia do fato: uma proposta de estudos sobre a memória histórica; Alcir Lenharo, A sacralização da política; Maria Luiza Tucci Carneiro, 0 antissemitismo na Era Vargas (1930-1945); Elizabeth Cancelli, O mundo da violência: a polícia na Era Vargas; Eliana de Freitas Dutra, $O$ ardil totalitário e a dupla face na construção do Estado Novo; Daniel Barbosa de Andrade Faria, 0 mito modernista. 
21 Segundo Arendt, somente duas atividades são políticas: a ação e o discurso, e delas nasce a esfera dos negócios públicos.

22 Há uma crítica um tanto ligeira a essa historiografia feita por Ângela de Castro Gomes em uma apresentação de livro de Jorge Ferreira, um dos grandes defensores do trabalhismo, do governo Jango como redentor da classe operária e do "liberalismo excludente". Nessa crítica, tanto Gomes como Ferreira dizem que as análises são reducionistas. Para Gomes, para entender Vargas e o "povo" (sic), sobre as questões da repressão e da propaganda política, "trata-se de considerá-las teórica e empiricamente equivocadas para dar conta do fenômeno que está sendo examinado, considerando-se sobretudo seus desdobramentos através do tempo"! (Gomes, 2005: 10). Nesse livro, Ferreira chega a afirmar que "afinados com os esquemas sociológicos dos teóricos do 'totalitarismo' (sic), alguns autores aproximam o governo Vargas dos regimes políticos de Hitler e Stalin (sic) (Lenharo, 1986; Cancelli, 1993)" (Gomes, 2005: 15).

23 Sobre a importância da documentação para reconstruir a história do movimento operário no Brasil, fruto de leitura aprofundada de Thompson, ver Hall e Pinheiro (1979; 1981).

\section{REFERÊNCIAS BIBLIOGRÁFICAS}

ARENDT, H. A condição humana. Rio de Janeiro: Forense Universitária, 1983.

BRESCIANI, M. S. M. As voltas de um parafuso. São Paulo: Brasiliense; AUPHIB, 1977. (Cadernos de Pesquisa Tudo é História, 2).

BURGUIÈRE, A. Da história evolucionista à história complexa. In: MORIN, E. A religação dos saberes: o desafio do século XXI. Rio de Janeiro: Bertrand Brasil, 2001. p. 359-368.

CANCELLI, E. Oliveira Vianna: mitos e utopias entre símbolos de brasilidade. Estudos Históricos, Rio de Janeiro, v. 2, n. 38, p. 135-136, jul./dez. 2006.

CANCELLI, E. O Brasil em Guerra Fria cultural. São Paulo: Intermeios, 2017.

CHALMERS, D. Internationalized domestic politics in Latin America: the Institutional Role of Internationally Based Actors. New York: Columbia University, 1993.

CHAUÍ, M. Apontamentos para uma crítica da Ação Integralista Brasileira. In: CHAUÍ, M.; FRANCO, M. S. C. Ideologia e mobilização popular. São Paulo: Paz e Terra, 1978.

DECCA, E. S.; VESENTINI, C. A. A revolução do vencedor. Revista de Ciência e Cultura, São Paulo, v. 29, n. 1, p. 70-85, jan. 1976.

FARIA, D. B. A. O mito modernista. Uberlândia: EdUFU, 2006.

FAUSTO, B. A Revolução de 1930: historiografia e história. São Paulo: Brasiliense, 1970. 
FONTES, P.; MACEDO, F. Entrevista com Michael Hall. Estudos Históricos, Rio de Janeiro, v. 29, n. 59, p. 813846, 2016. https://doi.org/10.1590/s2178-14942016000300013

FRANCO, M. S. C. 0 tempo das ilusões. In: CHAUÍ, M.; FRANCO, M. S. C. Ideologia e mobilização popular. São Paulo: Paz e Terra, 1978. p. 151-209.

FRANCO, M. S. C. Entrevista com Maria Sylvia de Carvalho Franco. [Entrevista cedida a]: Trans/Form/Ação, Marília, v. 34, n. spe, p. 167-177, 2011. Disponível em: <http://www.scielo.br/scielo.php?script=sci_ arttext\&pid=S0101-31732011000300007\&lng=en\&nrm=iso>. Acesso em: 24 mar. 2020. https://doi. org/10.1590/s0101-31732011000300007

FREUD, S. Fragment of an analysis of a case of hysteria ("Dora"). London: The Hoogart Press and The Institute of Psycho-Analysis, 1956. vii, p. 77-78. (Standard Edition of the Complete Psychological Works of Sigmund Freud).

GOMES, Â. C. A invenção do trabalhismo. São Paulo: Editora Vértice, 1988.

GOMES, Â. C. O redescobrimento do Brasil. In: LIPPI, L.; VELLOSO, M. P.; GOMES, Â. C. Estado Novo: ideologia e poder. Rio de Janeiro: Zahar, 1982. p. 109-150.

GOMES, Â. C. 0 populismo e as ciências sociais no Brasil: notas sobre a trajetória de um conceito. In: FERREIRA, J. (org.). O populismo e sua história: debate e crítica. Rio de Janeiro: Civilização Brasileira, 2001. p. 17-58.

GOMES, Â. C. Introdução. In: FERREIRA, J. O imaginário trabalhista: getulismo, PTB e cultura política popular 1945-1964. Rio de Janeiro: Civilização Brasileira, 2005. p. 9-17.

GOMES, Â. C. História e historiografia de A Revolução de 30. In: GOMES, Â. C. (org.). Leituras críticas sobre Boris Fausto. Belo Horizonte: Editora UFMG; São Paulo: Editora Fundação Perseu Abramo, 2008. p. 13-48.

HALL, M.; PINHEIRO, P. S. A classe operária no Brasil: 1889-1930. Volume 1: 0 movimento operário. São Paulo: Alfa-Ômega, 1979.

HALL, M.; PINHEIRO, P. S. Condições de vida e de trabalho, relações com os empresários e o Estado. São Paulo: Brasiliense; Campinas: FUNCAMP, 1981.

HUNTINGTON, S. Political order in changing societies. New Haven: Yale University Press, 1968.

KEOHANE, R. 0.; NYE JR., J. S. (eds.). Transnational Relations and World Politics. Cambridge: Harvard University Press, 1970/1971.

KRASNER, S. D. (ed.). International regimes. Ithaca: Cornell University Press, 1983.

LAMOUNIER, B. Ideologia em regimes autoritários: uma crítica a Juan Linz. Estudos Cebrap, São Paulo, n. 7, 68-92, jan./mar. 1974.

LEVINE, R. O Regime de Vargas: os anos críticos (1934-1938). Rio de Janeiro: Nova Fronteira, 1980.

LEVINE, R. M. Pai dos pobres?: o Brasil e a Era Vargas. São Paulo: Companhia das Letras, 2001.

LIPPI, L. Apresentação. In: LIPPI, L.; VELLOSO, M. P.; GOMES, Â. C. Estado Novo: ideologia e poder. Rio de Janeiro: Zahar, 1982. p. 7-13.

MUNAKATA, K. A legislação trabalhista no Brasil. São Paulo: Brasiliense, 1981. 
MUNAKATA, K. "Compromisso do Estado". Revista Brasileira de História, São Paulo, v. 4, n. 7, p. 58-71, 1984.

PINHEIRO, P. S. Política e trabalho no Brasil: dos anos 20 a 1930. São Paulo: Paz e Terra, 1975.

PINHEIRO, P. S. Estratégias da ilusão: a Revolução mundial e o Brasil (1922-1935). São Paulo: Companhia das letras, 1991.

ROMANO, R. Conservadorismo romântico: origem do totalitarismo. São Paulo: Editora Brasiliense, 1981. p. 22-23.

SANTOS, W. G. A práxis liberal no Brasil: proposta para reflexão e pesquisa. In: Ordem burguesa no Brasil. São Paulo: Duas Cidades, 1978. p. 9-61.

SOARES, G. [Resenha]. Revista Mexicana de Sociología, v. 34, n. 3/4, p. 928-929, jul./dec. 1972.

TORRES, C. A democracia e os regimes totalitários. In: CANCELLI, E. O Brasil em guerra fria cultural. São Paulo: Intermeios, 2017.

VELLOSO, M. P. Uma configuração do campo intelectual. In: LIPPI, L.; VELLOSO, M. P.; GOMES, Â. C. Estado Novo: ideologia e poder. Rio de Janeiro: Zahar, 1982. 